\title{
Influences of Rumen Fermentation and Bacterial Community Structure of Holstein and Jersey Steers by Dietary Changes
}

\author{
Seon-Ho Kim ${ }^{1}$, Mahfuzul Islam ${ }^{1,2}$, A-Rang Son ${ }^{1}$, SAng-Suk LeE $^{1 *}$
}

${ }^{1}$ Ruminant Nutrition and Anaerobe Laboratory, Department of Animal Science and Technology, Sunchon National University, Jeonnam 57922, Suncheon, Republic of Korea; ${ }^{2}$ Department of Microbiology and Parasitology, Sher-eBangla Agricultural University, Dhaka 1207, Bangladesh.

Seon-Ho Kim and Mahfuzul Islam contributed equally to this work.

\begin{abstract}
This study investigated the influence of diet types and breed of steers on rumen fermentation and bacterial community composition in Korea during the summer seasons. Three Holstein and 3 Jersey steers were fed a high forage (HF) and a high concentrate (HC) diet for two subsequent periods of 21 days under $2 \times 2$ factorial arrangements. The steers received HF diet had higher $\mathrm{pH}(P<0.05)$. Higher acetate concentration was recorded in the Jersey steers and those received HF diet; however, the Holstein steers and those received HC diet had higher propionate concentration $(P<0.05)$. The lowest A:P ratio was observed in the Holstein steers and those received HC $\operatorname{diet}(P<0.05)$. From Metataxonomic analysis, Bacteroidetes and Firmicutes were the most abundant bacterial phyla in both breeds and diets. Bacteroidetes was more abundant in the steers received HF diet while Firmicutes was increased with the HC diet. All four groups of steers had a distinct bacterial community with higher relative abundances. The principal component analysis (PCA) represented that the overall rumen bacterial community along with fermentation parameters varied among four groups. Overall results suggest that the rumen fermentation characteristics differ according to both diets and breeds which was influenced by a distinct bacterial community.
\end{abstract}

Keywords | Diet types, Holstein steer, Jersey steer, Volatile fatty acids, Rumen bacterial community

Received | August 09, 2021; Accepted | September 06, 2021; Published | January 15, 2022

*Correspondence | Sang-Suk Lee, Ruminant Nutrition and Anaerobe Laboratory, Department of Animal Science and Technology, Sunchon National University, Jeonnam 57922, Suncheon, Republic of Korea; Email: rumen@scnu.ac.kr

Citation | Kim S-H, Islam M, Son A-R, Lee S-S (2022). Influences of rumen fermentation and bacterial community structure of holstein and jersey steers by dietary changes. Adv. Anim. Vet. Sci. 10(3): 537-543.

DOI | http://dx.doi.org/10.17582/journal.aavs/2022/10.3.537.543

ISSN (Online) | 2307-8316

\section{INTRODUCTION}

A ccording to the third assessment report of the International Panel on Climate Change predicted that environmental temperature would rise by $1.4-5.8$ ${ }^{\circ} \mathrm{C}$ anywhere on the earth from 1990 to 2100 (MassonDelmotte et al., 2018). Indeed, the Korean peninsula experienced an increase by $2^{\circ} \mathrm{C}$ from 1992 to 2004 . In addition, the number of summer days in Korea increased between 1908 and 2009 (Kim,2010).Climate changes affects animal normal metabolism and physiological activities. Furthermore, ruminant diet, a combination of forage and concentrate, remarkably regulates the rumen fermentation and the microbial population within the rumen ecosystem. Rumen harbors different microorganisms viz. bacteria, protozoa, fungi and archaea that fermented a wide variety of ingested feedstuffs and produce volatile fatty acids (VFA) viz. acetate, propionate and butyrate which subsequently absorbed by the cattle as their energy metabolism and protein synthesis (Hook et al., 2010). Several factors such as heredity, host, age, physiological state, and sampling method affect rumen microbial diversity. Also, diet (Hua et al., 2017), feed additives (Uyeno et al., 2015), forage to concentrate ratio (Olijhoek et al., 2018), and feeding cycles (Wang et al., 2020) influence VFAs production and rumen microbial diversity. Among them forage content is 
of high importance to formulate an optimum ration for the improvement of animal diet. It was reported earlier that Bacteroidetes and Firmicutes were the top two abundant bacterial phyla in ruminants (Islam et al., 2021a, b; Kim et al., 2021; Ramos et al., 2021a, b). High concentrate (HC) diets decreases the relative abundance of rumen cellulotytic bacteria (Zhang et al., 2017). Furthermore, decrease in the dietary forage concentration increases the relative abundance of Firmicutes, while the opposite is true for the Bacteroidetes in ruminants (Ramos et al., 2021b). However, most previous research focused on the forage to concentrate ratio in the dairy cows and little is known about the steers. Also, the above-mentioned studies lack the information about temperature and humidity. It was reported earlier that, rumen bacterial diversity was affected by high temperature and humidity that leads to heat stress in ruminants (Zhao et al., 2019; Kim et al., 2020). Moreover, association of rumen fermentation and microbial community with dietary changes between steers especially during summer season was less documented. Therefore, the present study was designed to evaluate the influence of $\mathrm{HF}$ and $\mathrm{HC}$ diets on the rumen fermentation and bacterial community composition of Holstein and Jersey steers during summer season.

\section{MATERIALS AND METHODS}

\section{ANIMALS, EXPERIMENTAL DESIGN, AND DIET}

The animal experiment was conducted at the animal farm of Sunchon National University (SCNU), Jeonnam, South Korea. All animals used in this feeding trial were reviewed and approved by the SCNU Institutional Animal Care and Use Committee (IACUC approval number: SCNU-IACUC-2020-06). Three (3) non-cannulated Holstein $(690 \pm 10.50 \mathrm{~kg})$ and 3 Jersey $(550 \pm 15.75 \mathrm{~kg})$ steers were fed a $\mathrm{HF}$ and a $\mathrm{HC}$ diet for two subsequent periods of 21 days under a $2 \times 2$ factorial arrangements during the summer with recorded temperature humidity index (THI) about 85 . The temperature $\left({ }^{\circ} \mathrm{C}\right)$ and relative humidity (\%) of the experimental period were recorded by using a Testo $174 \mathrm{H}$ Mini data logger (West Chester, PA, USA $)$. The THI was calculated as THI $=(0.8 \times$ maximum ambient temperature $)+[\%$ relative humidity $/ 100 \times($ mean ambient temperature-14.4)] + 46.4 (Davis et al., 2003). The particular diets (Table 1) was offered once a day at 08:00 a.m. at a rate of 5\%-10\% of left-over diet. Seven days washing was performed between the two feeding trials.

\section{Sample collection, Processing and anAlysis of} RUMEN FERMENTATION CHARACTERISTICS

On the last day of each period, rumen fluids were collected from each of the steers $2 \mathrm{~h}$ before feeding by stomach tubing. The first $300 \mathrm{~mL}$ of rumen fluids were discarded in order to minimize contamination with saliva. Immediate after collection, the $\mathrm{pH}$ was measured using a $\mathrm{pH}$ meter (Seven Compact TM pH/Ion meter S220, Mettler Toledo, Switzerland immediately after collection). Rumen fluids were then transported to the laboratory and three separate aliquots for the analysis of ammonia nitrogen $\left(\mathrm{NH}_{3}-\mathrm{N}\right)$, volatile fatty acid (VFA), and rumen metagenomes were stored at $-80{ }^{\circ} \mathrm{C}$ until analysis. The $\mathrm{NH}_{3}-\mathrm{N}$ concentration was measured by using a Libra S22 spectrophotometer (CB40FJ; Biochrom Ltd., Cambourne, UK) (Chaney and Marbach, 1962). The VFA concentration was measured by using high-performance liquid chromatography (HPLC; Agilent Technologies 1200 series, Waldbronn, Germany) (Tabaru et al., 1988; Han et al., 2005).

Table 1: Feed ingredients and chemical compositions of different diets used in this experiment.

\begin{tabular}{|c|c|c|}
\hline \multirow[t]{2}{*}{ Ingredients } & \multicolumn{2}{|c|}{ Compositions (\% of DM) } \\
\hline & $\begin{array}{l}\text { High forage } \\
\text { diet }\end{array}$ & $\begin{array}{l}\text { High concentrate } \\
\text { diet }\end{array}$ \\
\hline Corn grain & 8.34 & 39.18 \\
\hline Corn gluten feed & 4.17 & 16.64 \\
\hline Wheat bran & 2.48 & 12.15 \\
\hline Lupin & 13.86 & 11.06 \\
\hline Oat hay & 4.97 & 19.58 \\
\hline Rice straw & 19.96 & - \\
\hline Tall fescue & 44.98 & - \\
\hline Limestone & 0.79 & 1.00 \\
\hline Vitamin premix & 0.09 & 0.09 \\
\hline Mineral premix & 0.10 & 0.10 \\
\hline Salt & 0.27 & 0.30 \\
\hline Total & 100.00 & 100.00 \\
\hline \multicolumn{3}{|c|}{ Chemical composition ( $\%$ of $\mathrm{DM}$ ) } \\
\hline DM (\% as fed basis) & 78.94 & 88.66 \\
\hline $\mathrm{CP}$ & 16.66 & 22.35 \\
\hline $\mathrm{CF}$ & 21.06 & 9.58 \\
\hline Crude fat & 2.27 & 4.37 \\
\hline Ash & 7.28 & 7.17 \\
\hline Calcium & 0.73 & 0.60 \\
\hline Phosphorus & 0.35 & 0.38 \\
\hline $\mathrm{NDF}$ & 52.57 & 23.44 \\
\hline $\mathrm{ADF}$ & 26.88 & 13.64 \\
\hline NFC & 21.22 & 42.67 \\
\hline
\end{tabular}

DM: dry matter; CP: crude protein; CF: crude fiber; NDF: neutral detergent fiber; ADF: acid detergent fiber; NFC: nonfibrous carbohydrates.

\section{MetataXonomic anALYSiS}

DNA from 12 rumen fluid samples were extracted by using a DNA Isolation Kit (PowerSoil ${ }^{\circledR}$; Cat. No.12888,MO BIO) following the manufacturer's protocol. After extraction, 4 pooled DNA samples were made from each group and sent 
to Macrogen Inc. (Seoul, South Korea) for metataxonomic analysis of the rumen bacteria. The amplicon library of each pooled sample, using two-step PCR amplification of the V3-V4 region of the $16 \mathrm{~S}$ rRNA genes with the primers Bakt_341F (5-AGATGTGTATAAGAGACAG-3) and Bakt_805R (5-GATGTGTATAAGAGACAGG-3) by Illumina 16S Metagenomic Sequencing Library protocols (Illumina, San Diego, CA, USA). Raw sequence data were trimmed using Trimmomatic (v0.38), and paired reads were merged using FLASH (1.2.11) software. Sequences shorter than $400 \mathrm{bp}$ were discarded. In order to identify and remove chimeric sequences rDnaTools (https:// github.com/PacificBiosciences/rDnaTools) was used. To avoid bias generated at different sequencing depths, samples were subsampled to an even depth of 10,000 sequences per sample. The filtered sequences were then clustered into operational taxonomic units (OTUs) at 97\% sequence similarity using CD-HIT-OTU. For taxonomic assignment, the representative sequence of each OTU was compared against the 16S Microbial DB of NCBI (https:// www.ncbi.nlm.nih.gov/r efseq/targetedloci/16S_process/) using BLASTN (v2.9.0+). The Shannon diversity index and Chao1 richness estimate were determined by using QIIME (v1.8).

\section{StaTistical ANALYsis}

All data of rumen fermentation characteristics were analyzed using the Mixed procedure in SAS (version 9.4; SAS Institute Inc., Cary, NC, USA) (SAS, 2013). Statistical significance is reported at $(P<0.05)$. The relative abundance of rumen bacteria at different taxa level was numerically compared among groups. Principal component analysis (PCA) score plot was made by using Minitab17 program (Minitab Ltd., UK) (Minitab Inc, 2010).

\section{RESULTS}

\section{RUMEN FERMENTATION CHARACTERISTICS}

The variation in the rumen fermentation parameters between Holstein and Jersey steers at different dietary conditions were analyzed and the results are presented in Table 2 . The rumen $\mathrm{pH}$ was significantly higher in the HF diet compared to $\mathrm{HC}$ diet in both the Holstein (6.66 vs $6.25)$ and Jersey (6.64 vs 6.31) steers $(P<0.05)$. The highest $\mathrm{NH}_{3}-\mathrm{N}(\mathrm{mg} / \mathrm{dl})$ concentration was observed in the Jersey steers received HC diet (8.82); however, not significant $(P$ $>0.05)$. The acetate and propionate concentration $(\mathrm{mM})$, and A:P ratio were significantly influenced by the diet types, and breeds. Significantly higher acetate was recorded in the Jersey steers and those steers received HF $\operatorname{diet}(P$ $<0.05)$. However, the Holstein steers and those steers received $\mathrm{HC}$ diet had significantly higher propionate concentration $(P<0.05)$. The lowest A:P ratio was observed in the Holstein steers and those steers received HC $\operatorname{diet}(P$
$<0.05)$. The butyrate and total VFA concentration $(\mathrm{mM})$ were significantly increased while steers received $\mathrm{HC}$ diet $(P<0.05)$.

\section{RUMEN BACTERIAL COMMUNITY COMPOSITIONS}

The richness and diversity of rumen microbes of Holstein and Jersey steers with $\mathrm{HF}$ and $\mathrm{HC}$ diets were analyzed and the results are presented in Table 3 . The observed OTUs, Chao 1, and Shannon index were numerically higher in the Holstein steers regardless of diet while the lowest value was observed in the Jersey steers received HC diet. At phylum level, the Bacteroidetes and Firmicutes were the most abundant bacterial phyla in both breeds and diets (Figure 1); however, their relative abundance varies according to dietary groups and breeds. The relative abundance of Bacteroidetes was higher in those steers received HF diet (72.37 vs $38.38 \%$ in Holstein and 75.15 vs $54.43 \%$ in Jersey steers) compared to HC diet. In contrast, the relative abundance of Firmicutes was increased when the steers received HC diet (from 25.36 to $59.80 \%$ and 23.40 to $45.00 \%$ in Holstein and Jersey steers, respectively).

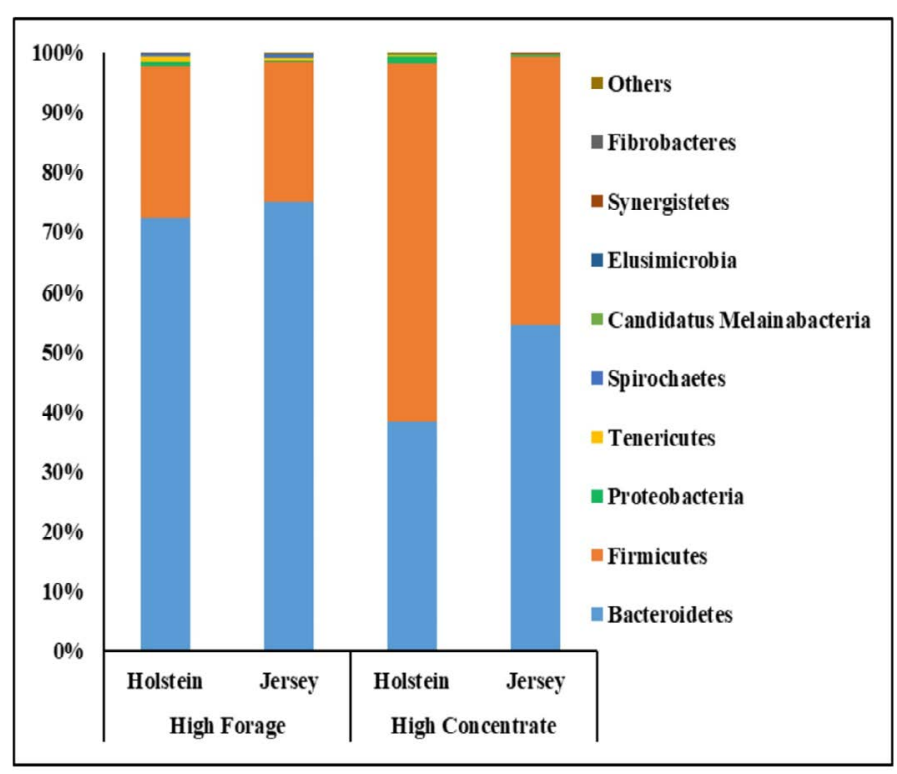

Figure 1: Phylum level relative abundance of rumen bacteria of Holstein and Jersey steers with high forage and concentrate diets.

At the species level, a total of 15 bacterial species, out of 248 species, were identified having relative abundance $>2 \%$ at least in one group (Figure 2). The Prevotella ruminicola was the most abundant bacterial species in both breeds and diets; however, the highest relative abundance of it was recorded in the Jersey steer when received HC diet (49.59\%). In contrast, the highest relative abundance of Ruminococcus bromii, Holdemania massiliensis, Barnesiella intestinibominis, and Vallitalea pronyensis were found in Holstein steer received $\mathrm{HC}$ diet. The highest relative 
abundance of Paludibacter propionicigenes and Prevotella brevis were observed in the Holstein steers received HF diet, while the highest relative abundance of Olivibacter sitiensis $(23.56 \%)$ was recorded in the Jersey steer received HF diet. The relative abundance of Flintibacter butyricus, Anaerobacterium chartisolvens, Intestinimonas butyriciproducens, and Eubacterium ventriosum were increased, while the relative abundance of Succiniclasticum ruminis was decreased with the $\mathrm{HC}$ diet regardless of breed. Also, the lowest relative abundance of Capnocytophaga cynodegmi was observed in the Jersey steers received HC diet. The PCA score plot represented that the overall rumen bacterial community along with the rumen fermentation parameters were different among the four groups (in both breeds and diets) (Figure 3).

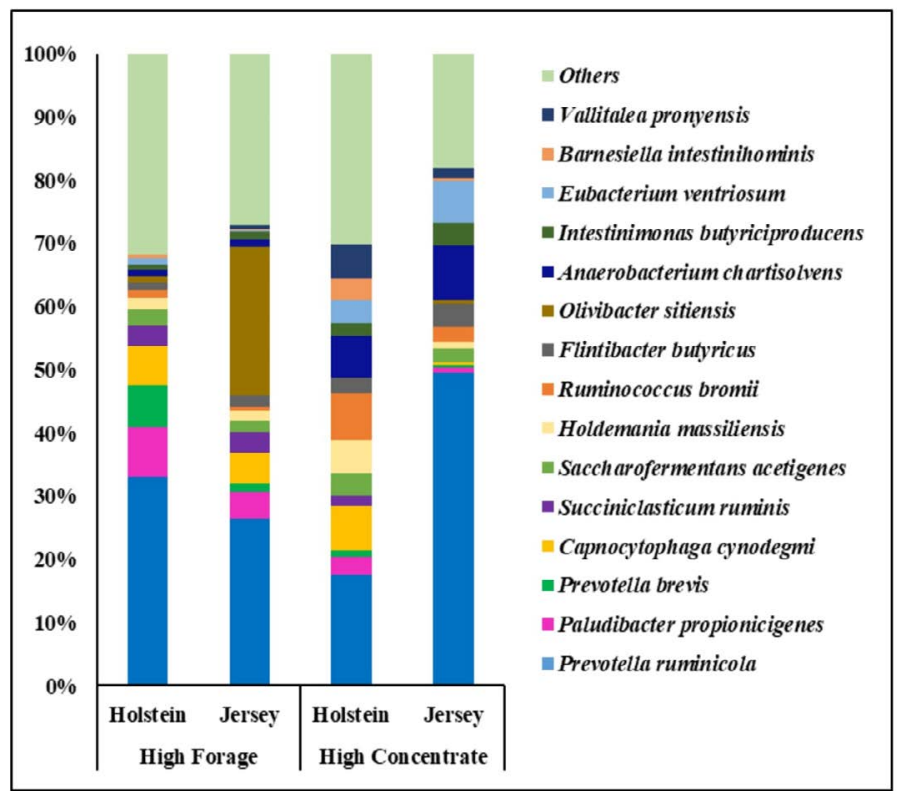

Figure 2: Relative abundance of top 15 rumen bacterial species of Holstein and Jersey steers with high forage and concentrate diets.

\section{DISCUSSION}

This study evaluated the influence of $\mathrm{HF}$ and $\mathrm{HC}$ diets on the rumen fermentation characteristic and rumen bacterial community composition of Holstein and Jersey steers during the summer season but not evaluated the effect of heat stress. The ruminal $\mathrm{pH}$ and the VFA correlated negatively, and feeding a $\mathrm{HC}$ diet decreased the $\mathrm{pH}$, while increased the VFA concentration in the rumen fluid of ruminants (Sato, 2016). In this study, we observed similar findings of low ruminal $\mathrm{pH}$ and high total VFA concentration in the rumen of steers received $\mathrm{HC}$ diet. In our study, we observed significantly higher acetate concentration in the steers received HF diet, while significantly higher propionate and numerically higher butyrate concentration in the steers received $\mathrm{HC}$ diet. These findings were strongly supported by Grubb and Dehority (1975) and Zhang et al. (2017) who reported that dietary changes from HF to HC reduced molar proportion of acetate and $\mathrm{A}: \mathrm{P}$ ratio, while increasing propionate and butyrate proportion. Our study also observed that acetate production was significantly higher in the Jersey steers, while propionate production in the Holstein steers. The reason might be due to the more efficient utilization of HF diet by the Jersey steer, while $\mathrm{HC}$ diet by the Holstein steers was consistent with the findings of Olijhoek et al. (2018).

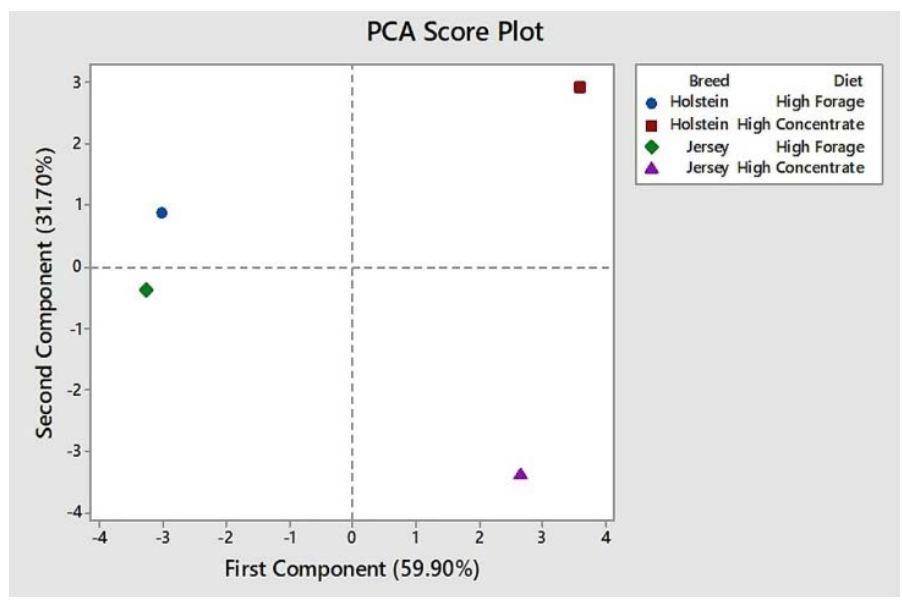

Figure 3: Principal component analysis (PCA) score plot represented the separation of both breeds and diets based on their rumen fermentation characteristics and species level relative abundance of rumen bacteria.

Table 2: Changes in the rumen fermentation characteristics of steers with different diets.

\begin{tabular}{lllllllll} 
Parameters & \multicolumn{3}{c}{ High forage } & \multicolumn{3}{c}{ High concentrate } & SEM & \multicolumn{3}{c}{ P-value } \\
& Holstein & Jersey & Holstein & Jersey & & Diet & Breed & Diet $\times$ Breed \\
$\mathrm{pH}$ & 6.66 & 6.64 & 6.25 & 6.31 & 0.104 & 0.012 & 0.866 & 0.717 \\
$\mathrm{NH}_{3}-\mathrm{N}(\mathrm{mg} / \mathrm{dl})$ & 7.36 & 7.18 & 7.57 & 8.82 & 0.813 & 0.304 & 0.546 & 0.420 \\
Acetate $(\mathrm{mM})$ & 58.62 & 60.62 & 54.84 & 56.99 & 0.425 & $<.001$ & 0.002 & 0.865 \\
Propionate $(\mathrm{mM})$ & 18.52 & 17.14 & 24.54 & 20.84 & 0.328 & $<.001$ & $<.001$ & 0.010 \\
Butyrate $(\mathrm{mM})$ & 10.81 & 10.62 & 12.06 & 12.13 & 0.235 & 0.001 & 0.806 & 0.594 \\
TVFA $(\mathrm{mM})$ & 87.95 & 88.37 & 91.44 & 89.97 & 0.555 & 0.004 & 0.426 & 0.170 \\
A: $\mathrm{P}$ & 3.16 & 3.54 & 2.24 & 2.74 & 0.042 & $<.001$ & $<.001$ & 0.273
\end{tabular}

SEM: standard error of the means; $\mathrm{NH}_{3}-\mathrm{N}$ : ammonia nitrogen; TVFA: total volatile fatty acid; A:P: acetate: propionate ratio. 
Table 3: Changes in the richness and diversity indices of the rumen bacterial community of steers with different diets.

\begin{tabular}{lllll} 
Parameters & \multicolumn{2}{c}{ High forage } & \multicolumn{2}{c}{ High concentrate } \\
& Holstein & Jersey & Holstein & Jersey \\
Observed OTUs & 585 & 542 & 598 & 502 \\
Chao1 & 628 & 579 & 645 & 526 \\
Shannon & 6.68 & 6.23 & 6.73 & 5.17
\end{tabular}

OUT: operational taxonomic unit.

The diversified rumen microbiome regulates the fermentation of feed particles with in the rumen. However, the low number of observed OTUs (ranges from 502 to 598), and Chao 1 (ranges from 526 to 645) might be due to the adverse effect of heat stress during the study period. Usually, the rumen microbial diversity is increasing with the increasing of forage portion in the diet (Wang et al., 2020). Likewise, the Jersey steers received HF diet had higher OTUs, Chao 1 and Shannon index in this study; however, Holstein steer had similar richness and diversity with both diets. In contrast, numerically higher OTUs, Chao 1 and Shannon index were observed in the Holstein steer compared to the Jersey steer. Similar findings also observed by Paz et al. (2016), who reported significantly higher Chao1, and observed OTU estimates in Holstein cows than that in Jersey lactating cows. In our study, we observed Bacteroidetes, and Firmicutes, together representing $>97 \%$ of all bacteria, were the highest bacterial phyla in both Holstein and Jersey steers with HF and HC diets which was consistent with the findings of several other ruminant studies (Bharanidharan et al., 2018; Xue et al., 2018). However, Bacteroidetes was more abundant in the steers received HF diet, while the relative abundance of Firmicutes was increased with $\mathrm{HC}$ diet. This finding is in agreement with the findings of Wang et al. (2020). Though Prevotella ruminicola was recorded as the most abundant bacterial species in both breeds and diets; however, highest relative abundance in Jersey steer with $\mathrm{HC}$ diet might be associated with their highest $\mathrm{NH}_{3}-\mathrm{N}$ concentration. This is because Prevotella spp. are the major species triggers proteolytic activity to breakdown of protein rich diets in the rumen (Bharanidharan et al., 2018; Xue et al., 2018). In this study, the highest relative abundance of Ruminococcus bromii, Holdemania massiliensis, Barnesiella intestinihominis and Vallitalea pronyensis in Holstein steer received HC diet and Olivibacter sitiensis in the Jersey steer received HF diet suggested the influence of both breeds and diets on rumen bacterial community. The $I$. butyriciproducens and $F$. butyricus are the two important butyrate producing bacteria in ruminants (Bui et al., 2016; Petri et al., 2018). The higher relative abundance of those bacteria in the steers received HC diet might be associated with their significantly higher butyrate production. In addition to this, both breeds with different diets had distinct group of bacterial species having higher relative abundances compared to other groups. The PCA score plot further supported that overall rumen bacterial community along with their fermentation products were distinct among the four different groups.

\section{CONCLUSIONS AND RECOMMENDATIONS}

In conclusion, the rumen fermentation characteristics differs according to the variation in the diets and breeds which was regulated by a distinct bacterial community with higher relative abundances. These results strengthen our current understanding of rumen fermentation and bacterial community composition of ruminant steers at different dietary condition. Future study included detail metagenomics and metabolomics analysis with large number of animals at different environmental conditions to explore the complex metabolic pathways of ruminants.

\section{ACKNOWLEDGEMENTS}

This research was supported by the National Research Foundation of Korea (NRF-2021R1C1C2014102), Republic of Korea.

\section{NOVELTY STATEMENT}

This is the first study focused the effects of dietary changes on the rumen fermentation characteristics and bacterial community composition of steers of the dairy breed particularly in the summer.

\section{AUTHOR'S CONTRIBUTION}

S-HK, MI, and S-SL designed and conceptualized the experiments. S-HK, MI, and A-RS performed the animal experiment and laboratory tests. S-HK, MI, and S-SL performed data checking. S-HK, and MI performed statistical analysis. MI wrote the first draft of the manuscript which was revised by S-HK, MI, and S-SL. All authors contributed to the final manuscript revision and approval.

\section{CONFLICT OF INTEREST}

The authors have declared no conflict of interest.

\section{REFERENCES}

Bharanidharan R, Arokiyaraj S, Kim EB, Lee CH, Woo YW, Na Y, Kim D, Kim KH (2018). Ruminal methane emissions, metabolic, and microbial profile of Holstein steers fed forage and concentrate, separately or as a total mixed ration. Plos One, 13(8): e022446. https://doi.org/10.1371/journal. pone.0202446 
Bui TPN, Shetty SA, Lagkouvardos I, Ritari J, Chamlagain B, Douillard FP, Paulin L, Piironen V, Clavel T, Plugge CM, de Vos WM (2016). Comparative genomics and physiology of the butyrate-producing bacterium Intestinimonas butyriciproducens. Environ. Microbiol. Rep., 8: 1024-1037. https://doi.org/10.1111/1758-2229.12483

Chaney AL, Marbach EP (1962). Modified reagents for determination of urea and ammonia. Clin. Chem., 8:130132. https://doi.org/10.1093/clinchem/8.2.130

Davis MS, Mader TL, Holt SM, Parkhurst AM (2003). Strategies to reduce feedlot cattle heat stress: Effects on tympanic temperature. J. Anim. Sci., 81: 649-661. https:// doi.org/10.2527/2003.813649x

Grubb JA, Dehority BA (1975). Effects of an Abrupt Change in Ration from All Roughage to High Concentrate upon Rumen Microbial Numbers in Sheep. Appl. Microbiol., 30: 404-412. https://doi.org/10.1128/am.30.3.404-412.1975

Han SK, Kim SH, Shin HS (2005). UASB treatment of wastewater with VFA and alcohol generated during hydrogen fermentation of food waste. Process Biochem., 40: 2897-2905. https://doi.org/10.1016/j.procbio.2005.01.005

Hook SE, Wright ADG, McBride BW (2010). Methanogens: Methane producers of the rumen and mitigation strategies. Archaea,2010:50-60.https://doi.org/10.1155/2010/945785

Hua C, Tian J, Tian P, Cong R, Luo Y, Geng Y, Tao S, Ni Y, Zhao R (2017). Feeding a high concentration diet induces unhealthy alterations in the composition and metabolism of ruminal microbiota and host response in a goat model. Front. Microbiol., 8: 1-12. https://doi.org/10.3389/ fmicb.2017.00138

Islam M, Kim SH, Ramos SC, Mamuad LL, Son AR, Yu Z, Lee SS, Cho YI, Lee SS (2021a). Holstein and Jersey steers differ in rumen microbiota and enteric methane emissions even fed the same total mixed ration. Front. Microbiol., 12:601061. https://doi.org/10.3389/fmicb.2021.601061

Islam M, Kim SH, Son A, Ramos SC, Jeong CD, Yu Z, Kang SH, Cho YI, Lee SS, Cho KK, Lee SS (2021b). Seasonal Influence on Rumen Microbiota, Rumen Fermentation, and Enteric Methane Emissions of Holstein and Jersey Steers under the Same Total Mixed Ration. Animals, 11:1184. https://doi.org/10.3390/ani11041184

Kim DH, Kim MH, Kim SB, Son JK, Lee JH, Joo SS, Gu BH, Park T, Park BY, Kim ET (2020). Differential dynamics of the ruminal microbiome of jersey cows in a heat stress environment. Animals, 10: 1-19. https://doi.org/10.3390/ ani11010019

Kim ES (2010). Statistical interpretation of climate change in Seoul, Korea, over the last 98 years. J. Ecol. F. Biol., 33: 3745. https://doi.org/10.5141/JEFB.2010.33.1.037

Kim S.-H, Islam M, Son AR, Lee SS, Kang SH, Cho YI, Park KW, Lee SS (2021). In vitro Assessment of Rumen Inocula between Jersey and Holstein Steers with Forage and Concentrate Substrates. J. Agric. Life Sci., 55: 89-96. https://doi.org/10.14397/jals.2021.55.3.89

Masson-Delmotte V, Zhai P, Pörtner HO, Roberts D, Skea J, Shukla PR., et al. (2018). Global Warming of 1.5 Degree Celsius: IPCC Special Report on the Impacts of Global Warming of 1.5 Degree Celsius. Intergov. Panel Clim. Chang. Geneva, Switzerland, Report. https//www. ipcc. ch/ sr15.

Minitab Inc (2010). Minitab 17 statistical software. URL:[Computer software]. State College, PA: Minitab, Inc. (www. minitab. com).
Olijhoek DW, Løvendahl P, Lassen J, Hellwing ALF, Höglund JK, Weisbjerg MR, Noel SJ, McLean F, Højberg O, Lund $P$ (2018). Methane production, rumen fermentation, and diet digestibility of Holstein and Jersey dairy cows being divergent in residual feed intake and fed at 2 forage-toconcentrate ratios. J. Dairy Sci., 101: 9926-9940. https:// doi.org/10.3168/jds.2017-14278

Paz HA, Anderson CL, Muller MJ, Kononoff PJ, Fernando SC (2016). Rumen bacterial community composition in holstein and jersey cows is different under same dietary condition and is not affected by sampling method. Front. Microbiol., 7: 1-9. https://doi.org/10.3389/fmicb.2016.01206

Petri RM, Pourazad P, Khiaosa-ard R, Klevenhusen F, MetzlerZebeli BU,Zebeli Q (2018). Correction: Temporal dynamics of in situ fiber-adherent bacterial community under ruminal acidotic conditions determined by $16 \mathrm{~S}$ rRNA gene profiling. PLoS One, 12:8 (e0182271) DOI 10.1371/journal. pone.0182271. PLoS One 13: 1-18. https://doi.org/10.1371/ journal.pone.0204600

Ramos SC, Jeong CD, Mamuad LL, Kim SH, Son A, Miguel MA, Islam M, Cho YI, Lee SS (2021a). Enhanced ruminal fermentation parameters and altered rumen bacterial community composition by formulated rumen buffer agents fed to dairy cows with a high-concentrate diet. Agriculture, 11: 554. https://doi.org/10.3390/agriculture11060554

Ramos SC, Jeong CD, Mamuad LL, Kim SH, Kang SH, Kim ET, Cho YI, Lee SS, Lee SS (2021b). Diet transition from high-forage to high-concentrate alters rumen bacterial community composition, epithelial transcriptomes and ruminal fermentation parameters in dairy cows. Animals, 11: 838. https://doi.org/10.3390/ani11030838

SAS (2013). Statistical Analysis Systems for windows, version 9.4, SAS Institute Inc., Cary, NC, USA.

Sato $S$ (2016). Pathophysiological evaluation of subacute ruminal acidosis (SARA) by continuous ruminal $\mathrm{pH}$ monitoring. Anim. Sci. J., 87: 168-177. https://doi.org/10.1111/ asj. 12415

Tabaru H, Kadota E, Yamada H, Sasaki N, Takeuchi A (1988). Determination of volatile fatty acids and lactic acid in bovine plasma and ruminal fluid by high performance liquid chromatography. Jap. J. Vet. Sci., 50:1124-6. Available at: http://www.mendeley.com/research/geology-volcanichistory-eruptive-style-yakedake-volcano-group-centraljapan/, https://doi.org/10.1292/jvms1939.50.1124

Uyeno Y, Shigemori S, Shimosato T (2015). Effect of probiotics/ prebiotics on cattle health and productivity. Microbes Environ., 30: 126-132. https://doi.org/10.1264/jsme2. ME14176

Wang L, Zhang G, Li Y, Zhang Y (2020). Effects of high forage/ concentrate diet on volatile fatty acid production and the microorganisms involved in VFA production in cow rumen. Animals, 10(2): 223. https://doi.org/10.3390/ani10020223

Xue M, Sun H, Wu X, Guan LL, Liu J (2018). Assessment of rumen microbiota from a large dairy cattle cohort reveals the pan and core bacteriomes contributing to varied phenotypes. Appl. Environ. Microbiol., 84: 1-13. https:// doi.org/10.1128/AEM.00970-18

ZhangJ, Shi H, Wang Y, Li S, Cao Z,Ji S, He Y, Zhang H (2017). Effect of dietary forage to concentrate ratios on dynamic profile changes and interactions of ruminal microbiota and metabolites in holstein heifers. Front. Microbiol., 8: 2206. https://doi.org/10.3389/fmicb.2017.02206

Zhao S, Min L, Zheng N, Wang J (2019). Effect of heat stress 
